\title{
A case study of asthma care in school age children using nurse-coordinated multidisciplinary collaborative practices
}

This article was published in the following Dove Press journal:

Journal of Multidisciplinary Healthcare

8 April 2015

Number of times this article has been viewed

\section{Susan Procter ${ }^{1}$ \\ Fiona Brooks ${ }^{2}$ \\ Patricia Wilson ${ }^{3}$ \\ Carolyn Crouchman' \\ Sally Kendall ${ }^{2}$}

'Faculty of Society and Health, Buckinghamshire New University, High Wycombe, UK; ${ }^{2}$ Centre for Research in Primary and Community Care (CRIPACC), University of Hertfordshire, Hatfield, UK; ${ }^{3}$ Centre for Health Services Studies, University of Kent, Canterbury, UK
Correspondence: Susan Procter Faculty Society and Health, Buckinghamshire New University, 106 Oxford Road, Uxbridge, Middlesex UB8 INA, UK Tel +4401494522141 ext 5129 Mob+440782505 27II

Email s.procter@bucks.ac.uk
Aim: To describe the role of school nursing in leading and coordinating a multidisciplinary networked system of support for children with asthma, and to analyze the strengths and challenges of undertaking and supporting multiagency interprofessional practice.

Background: The growth of networked and interprofessional collaborations arises from the recognition that a number of the most pressing public health problems cannot be addressed by singlediscipline or -agency interventions. This paper identifies the potential of school nursing to provide the vision and multiagency leadership required to coordinate multidisciplinary collaboration.

Method: A mixed-method single-case study design using Yin's approach, including focus groups, interviews, and analysis of policy documents and public health reports.

Results: A model that explains the integrated population approach to managing school-age asthma is described; the role of the lead school nurse coordinator was seen as critical to the development and sustainability of the model.

Conclusion: School nurses can provide strategic multidisciplinary leadership to address pressing public health issues. Health service managers and commissioners need to understand how to support clinicians working across multiagency boundaries and to identify how to develop leadership skills for collaborative interprofessional practice so that the capacity for nursing and other health care professionals to address public health issues does not rely on individual motivation. In England, this will be of particular importance to the commissioning of public health services by local authorities from 2015.

Keywords: leadership, multiagency, public health, school nursing, whole systems

\section{Introduction}

This paper presents the findings from a case study which formed one of seven case studies designed to identify the nursing contribution to chronic disease management. ${ }^{1}$ All of the case studies were selected using criteria which indicated innovation and nurse leadership. Findings from the other six case studies, reported elsewhere, ${ }^{2}$ highlighted considerable fragmentation in the coordination of services. The case study presented here is reported separately because it provides an exemplar of nursing leading integrated whole-system service provision for children with asthma.

\section{Background}

The growth of networked and partnership collaborations arises from the recognition that a number of the most pressing public health problems cannot be addressed by single-agency interventions. ${ }^{3}$ Childhood asthma falls into this category. Asthma is one of the most common long-term conditions affecting young people. The first UK national review of asthma deaths found that two thirds of deaths could be prevented 
with better care and that $96 \%$ of children who died did not receive care based on good practice. ${ }^{4}$ There is evidence that peaks in hospital admission among school-age children coincides with the start of the school year. ${ }^{5}$

A range of initiatives have been evaluated drawing on educational and population-based principles to improve asthma management among school age children. These include education initiatives, ${ }^{6,7}$ asthma clubs, ${ }^{8}$ population screening, ${ }^{9}$ combined population screening and education, ${ }^{10,11}$ and the introduction of a consulting physician with a specific remit to reduce school absenteeism. ${ }^{12}$

Whilst school nurses have a history of working with children and families, as well as in schools to provide asthma education and support, the role of teachers in supporting parents to manage the health of school children in England is, however, unclear and in some cases contradictory. ${ }^{13,14}$ The law in England says that teachers receive delegated authority from parents necessary for maintaining the child's welfare. However, as Crouchman ${ }^{13,14}$ points out, there is no obligation for teaching staff, including physical education staff, in England to do any first aid training.

Multiagency collaboration to address public health issues such as childhood asthma is increasingly being advocated. ${ }^{15}$ There is a growing body of international knowledge about the governance, management and leadership qualities, and behaviors required for managers and clinicians to work effectively in networked or partnership collaborations. ${ }^{16-18}$ However, detailed case studies have also identified significant barriers to effective teamwork, with research indicating a cautiousness among many professionals to engage in interprofessional collaboration. ${ }^{18-20}$

This paper describes a nurse-led population health care service for school children with asthma in which multi-professional interagency collaboration featured strongly. Using Yin's ${ }^{21}$ approach to explanatory case study methodology, this case study describes the role of nursing leadership in coordinating collaborative approaches to health problems which require multiagency integration. It describes some of the challenges and tensions between the different parts of the whole system which need to be addressed in order to develop a more integrated approach to care delivery.

\section{The study}

\section{Aim}

To describe the role of school nursing in leading and coordinating a multidisciplinary, networked system of support for children with asthma, and to analyze the strengths and challenges of undertaking and supporting collaborative interprofessional practice.

\section{Design}

The findings presented here are taken from one of seven case study sites.

Yin's ${ }^{21}$ case study methodology was drawn upon to direct the fieldwork and the data analysis of the multiple sources of evidence.

\section{Sample/participants}

The case study was selected following a systematic mapping of publicly available information on nursing management of long-term conditions from across England and Wales. Leaders of services were invited to present a description of their service at a conference hosted by the research team and attended by service users. Case studies for in-depth analysis were selected by consensus methods involving all conference participants. A fuller account of sampling and case study selection is given by Wilson et al. ${ }^{22}$

\section{Data collection}

Semistructured audio recorded face-to-face or telephone interviews were used to collect the data. Interviews lasted between 30 minutes and 1 hour and were conducted with eleven practitioners including the asthma coordinator, who was the lead school nurse, and ten school health advisors, all of whom had a school nursing qualification. All interviews were audio-recorded and transcribed verbatim. Secondary data analysis was undertaken of operational and strategic plans as well as annual reports from the Primary Care Trust (PCT) to identify the relationship between the school nursing service and the organizational objectives of the PCT and commissioners. A PCT was the organizational unit within the National Health Service (NHS) for England at the time of the study whereby services for primary care were both provided and commissioned. In 2010, there was organizational change and transition from PCTs to clinical commissioning groups and community service providers.

The researchers were not able to undertake interviews with general practitioners (GPs), although this would have added a further perspective on the strategy and is recognized as a limitation.

\section{Ethical considerations}

Informed consent was obtained from all participants who were made aware that their contribution may be published. All participants were given the opportunity to opt out following 
participation. Ethics and research governance approval was obtained through the NHS prior to data collection.

\section{Data analysis}

The interview data from practitioners were open-coded using N-Vivo software. These data were then subjected to thematic analysis. The reliability of the themes identified was checked by the authors who were involved in data collection and analysis.

\section{Validity and rigor}

The findings were independently reviewed by two members of the research team and discussed by the team as a whole. Disconfirming statements were searched for. An expert steering group which included patients reviewed drafts of the findings and gave critical feedback.

\section{Findings}

The case study covered a primary and secondary school-age population of approximately 40,000 children within a mainly urban area of the West Midlands with a total population of approximately 305,000 . The area was characterized by a serious shortage of GPs and poor air quality. Yet, despite these problems, the emergency admission rate of children to hospital in this area was 49 compared to the standardized national average in England of 100 (rate of hospital admissions per head of population, standardized to account for regional differences in age and sex, with the average for England assigned a rate of 100).

\section{Public policy influences on local service delivery}

The asthma service was developed in response to a number of policy drivers which impacted on different provider organizations across the system:

- The Public Health Report for 2007: this report records the air quality for the local area. Its findings indicate that at the time of the study, nitrogen oxide and small particle emissions were well above the UK mean. Evidence suggests that both these emissions can have a harmful effect on the respiratory system and that nitrogen oxide has a particularly damaging effect on people with asthma, increasing hospital admissions for children. ${ }^{23,24}$

- The education system: as a result of government policy, ${ }^{25}$ all schools in England are subject to specific targets to reduce school absenteeism.

- The publication of the National Service Framework for Children and Maternity Services ${ }^{26}$ by the UK Government included a multiagency partnership exemplar pathway for asthma in childhood.

- Every Child Matters ${ }^{27}$ provided an integrated framework of objectives for children's services, which health, education, and social services in England were required to meet in an attempt to create an integrated policy response to the multiple complex needs of children and young people. Specific advice was issued to schools in relation to children with asthma. This advised that children should have access to their reliever inhalers, that all schools should have an asthma policy, and that all teaching staff, but particularly teachers who supervise physical exercise, should have training once a year or be provided with information on how to care for a child with asthma. ${ }^{27}$

\section{The origins of the school asthma service}

The development of a school asthma service in this case study began pre-2000. Community nurses had recognized the need to work with schools to meet the health needs of school-aged children with asthma. However, it was only following the appointment of the current school nurse asthma coordinator in 2000 that their aspirations were taken forward strategically:

We've been trying to set this policy up going back to sort of 1997 ... we couldn't really take it forward ... [Asthma coordinator] came along and obviously with this excellent enthusiasm and interest in asthma and sort of really pushed the service forward. [School health advisor 1]

The initial stimulus for the school asthma strategy was the recognition by key stakeholders including health and education services of the need to provide a more integrated, seamless service for managing childhood asthma. The objectives of the service mirrored policy objectives and were designed to empower children and their families to manage asthma with confidence, reduce hospital admission, and reduce absenteeism from school.

The development of the school asthma service was aided by the charity Asthma UK, which provided 12 months' funding to pump prime the asthma coordinator role. The role was subsequently funded by the local primary care provider. The multiagency strategy was launched by the primary care service in 2003 as described by the asthma coordinator:

The priority when I came into this post was to get $100 \%$ of schools, you know of all [town] schools to have an 
asthma policy. When I came into post we had $76 \%$ of schools signed up to the [town] School's asthma policy, we've now got approximately $96 \%$ so there are I think three outstanding schools at the moment and that's just a time issue for me to actually get round individually to those schools and persuade them to come on board ... We have the full backing of the local authority on it, it's a jointly ratified policy between health and education. [Asthma coordinator]

\section{The structure of the school asthma service}

The school asthma service is led by the asthma coordinator who is based in primary care. The asthma coordinator is a registered nurse and sick children's nurse, as well as a school nurse. She coordinates a team of school health advisors, most of whom are registered as school nurses.

The school health advisors are responsible for a number of schools across the town. Each school has identified schools-based asthma support workers who could be teachers, first aid workers, or teaching assistants. The asthma support workers work with their school advisor to implement the school asthma policy. Collectively, support workers and their school health advisor carry a caseload of children with asthma. All advisors and support workers have had specialist training in asthma management and are regularly updated as part of their professional development.

\section{The organization of the school asthma service}

All children with asthma admitted to a school in the area are registered on an asthma register:

Any new children coming into school now, the parents will be sent the asthma information form and hopefully they'll be put on the register. [School health advisor 2]

The school nurses and support workers made frequent reference to the asthma register of school-aged children and reported the register as a valuable tool that enabled them to identify children with asthma. The school nurses also referred to the way in which they used a data system to reconfigure service delivery, in particular with primary care:

I think one of the main issues was obviously parents not taking children to their asthma clinics, and we were actually saying well maybe we could be seeing the children and the parents at school. [School health advisor 2]
As part of the school asthma service, the asthma coordinator had negotiated the availability of emergency asthma medication in each school:

And also within our asthma policy we will provide for any school that wants one, an emergency salbutamol inhaler and spacer device ... we do it as safely as we possibly can, we have a robust risk management strategy, we have a consultant community pediatrician who takes responsibility for placing the drug within the school, the drug is only available [to children] whose names are on the school asthma register, whose parents have signed a consent form for the use of the drug. It's kept in a safe place within the school and it's monitored, it's use is monitored. [Asthma coordinator]

At the time the study was conducted, this was an innovative strategy for the management of asthma in schools. In September 2014, the Department of Health for England produced guidance for schools to enable them to use an emergency salbutamol inhaler without prescription. ${ }^{28}$

The audit of emergency inhaler use from January 2006 to December 2006 indicated that emergency inhalers were used in schools 106 times. The close monitoring of the use of the emergency inhaler was used to identify and provide additional support for children and families who were having difficulty with asthma management:

So it's [monitoring the use of the emergency inhaler] actually quite an effective tool in asthma management because if a child is using the school's emergency device we want to know why. Why are they using it and it's down to the school nurses to check those records on a monthly basis, why has Johnnie used that inhaler twice in the last month? Why didn't he have his own inhaler? And that then generates a work load for the school nurse. [Asthma coordinator]

Throughout the year, the record of inhaler use enables the school asthma advisors to identify the children who are regularly attending school without their inhalers. This triggers a follow-up meeting with the child's family to identify why this is happening and provide additional education and support. The results of the audit are disseminated across the case study area and between schools and GP practices.

The school asthma registers and audit data formed an important tool used by school health advisors to target interventions for asthma management. The development of a local patient record and data system can be at odds with more centralized electronic patient record systems; they also suffer from limitations in technical support and local expertise. 
However, the sense of ownership the team had developed was creating enhanced understanding of local needs and driving innovations in practice. The asthma coordinator was seen as the champion of much of this work as clearly identified above.

\section{The asthma coordinator role}

The asthma coordinator was seen as key to the service. She provided clear strategic leadership relating to policy and practice concerning the management of asthma in young people. This was welcomed by the School Health Advisors who were enabled to undertake their role by being able to access and work with the specialist asthma coordinator. More generic community nurses were also able to access specialist knowledge from the asthma coordinator which enhanced their service. This reflects the work of Brooks et $\mathrm{al}^{29}$ who describe a whole network of coordinated activities which fall within the responsibility of the "navigator" role. However, in this case, there was little evidence of succession planning for the role of the asthma coordinator; neither was there evidence of service reconfiguration to adopt a more public-health-focused model. Dependence on a key, single individual was therefore a weakness of the current service.

The school asthma strategy described above had to demonstrate both impact and outcomes for the local health economy. It was clear that although there was a willingness to set up a school asthma service across core organizations, the asthma coordinator was actually key to the realization of this aspiration. Without her expert knowledge, vision, problem solving, and ability to develop and get policies and procedures ratified across all partner agencies, the service might not have been implemented.

The actual nurse time involved in developing and implementing the strategy must also be considered. We were unable to collect precise data on this, but the asthma coordinator role was a full time nursing role and the ten school health advisors had varying full time equivalencies, of which only some of their time was concerned with the asthma strategy. Whilst the cost of this nursing input on an annual basis is relatively high, it can be argued that cost savings could also be made through the reduction in hospital admissions reported for the PCT. As with all service evaluation, this may not be a direct consequence of the asthma service, but there were no other initiatives in the area that could have accounted for the relatively low hospital admission rate compared with other similar areas.

The coordination of central government policy directives towards a focus on health outcomes for children provided a rationale for expenditure that could be used by the local team to implement their vision. Without these policy initiatives, this service might not have received the support from local stakeholders required to realize these outcomes.

\section{Whole system engagement}

The school asthma service is based on public health principles of increasing the capacity across the system of support to manage asthma by raising awareness and education of health service staff, school staff, parents, and children, and as described by the asthma coordinator below:

Well another group before me had decided that we needed asthma policies in schools and they were really struggling, with the barriers between health and education really. And I sort of came on board and just ended up leading that project, just pushing it through and we've now got a ratified policy, our school asthma policy. [Asthma Coordinator]

The asthma coordinator working with her team of school health advisors and asthma support workers are working towards enabling the child and family to navigate ${ }^{29}$ their way through the health and education network. The goal is to provide an integrated service in which the child with asthma can move seamlessly between NHS, school, and home:

So what we're actually hoping to achieve at the end of this is some sort of framework integrated care pathway, I'm not really sure what it will be called. Some sort of framework, which has basically got the child or young person and their family at the very heart of the document, really in the center of it all. [School health advisor 1]

There was considerable evidence of collaborative working across agencies including health, education, voluntary sector, and the community. Within the health sector, collaboration between emergency departments, GP practices, and hospital inpatient departments was underway. This was supported by the lead for Healthy Schools on the Primary Care Directorate for Children's Services, who commented that they had been working on:

the concept of healthy schools in [town] since 1994 so it predates the National Healthy Schools Program ... And we have all of our schools signed up and committed including our referral units and we also work with the colleges and it's very much about promoting and developing the concept of health for children within the school setting and associated settings. [Local authority lead nurse for Healthy Schools] 
The healthy schools award is a national initiative which involves a formal accreditation process.

Whilst all the schools within the case study area were involved in the whole-system strategy, there was more difficulty integrating GPs and primary care as well as all other parts of the health system into the asthma strategy:

we've just set up the Paediatric Respiratory Forum and what that has done has brought together a range of professionals from primary and secondary care, community services, education, safeguarding children, which is another big area. Brought all of these people together and asked them to look at children with asthma in their area, what we can do about it, and how we can bring it all together basically.

[Asthma coordinator]

A key performance indicator for primary care in the UK is the Quality Outcomes Framework (QOF). GPs are able to claim additional funding if they can demonstrate that they have met their QOF targets. QOF accounts for approximately $25 \%$ of general medical service income. QOF points are awarded for asthma targets, which include minimally keeping an asthma register through to monitoring those diagnosed with asthma and ensuring they receive an annual review. However, QOF targets are not specific to childhood asthma although children are included in them.

There was evidence that primary care is the weakest link in system-of-care delivery:

It's very difficult to communicate with GP's isn't it, because we're not just actually covering the schools in a certain catchment GP area. Whereas the health visitor would be working with a particular GP and could do that liaison so much better, we're dealing with so many GP's, children are coming from all over the borough to certain schools and that is a problem sometimes. [School health advisor 3]

\section{Discussion}

This case study provides a model of how nurses can develop a system of care which reflects the principles of a public healthorientated primary care system. To make this work effectively, political and organizational commitment, networked leadership, and above all a vision of what they are trying to achieve is required. Collectively, this created a local workforce with well-developed teamwork skills and the ability to work across multiple agencies. However, establishing this service was highly dependent on the vision and energy of a single individual, which makes the replication of the service difficult to achieve. In a review of cross-sector partnerships, Andrews and Entwistle ${ }^{30}$ found that public-public partnerships were positively associated with public service efficiency, equity, and effectiveness, indicating the potential of these partnerships to effectively address cross-agency population needs. However, as this study demonstrated, actually establishing effective multiagency partnership working requires the organizations involved to develop a shared vision beyond their individual organizational missions. Coordinated central government policies provided incentives for organizations to collaborate.

In reviewing the case study, it is clear that it conforms to many of the attributes identified by Mikkelsen-Lopez et al ${ }^{16}$ required to create governance across health systems. These include a long-term strategic vision led by local clinical stewards (in this case the asthma coordinator) based on transparent information translated into transparent policies (the school asthma register and the inhaler policy), rules (about who can use the inhaler and follow-up of those children who do use it), and incentives (eg, to meet government targets to reduce school absenteeism).

The case study demonstrates that adherence to central government policies and a desire to meet centrally imposed targets, combined with an organic practice development methodology, has been instrumental in enabling the development of an effective local, networked asthma service. These factors have also sustained the service through some of the organizational complexity and constraints imposed by constant NHS reorganization.

Problems remain, however: the local data system set up by the service did not interface with more centralized patient and pupil records; engagement with primary care, which was also responding to a different set of government imposed targets, was still a problem; and there was an apparent lack of succession planning for the asthma coordinator. Despite these problems, there was a real sense of innovation and purpose within the network that provides optimism that such barriers can be overcome.

Front-line stewardship of service redesign is seen as a key attribute of all networked systems. ${ }^{16,18,20,30}$ This paper illustrates the potential contribution primary care nurses could make to realizing collaborative professional practice within a networked system of provision. ${ }^{17}$ The model still, however, reflects a single-disease-orientated approach to service integration; it is not clear if this model could be replicated simultaneously over a number of different long-term children's illnesses such as diabetes, epilepsy, and sickle cell disease alongside asthma. Further theoretical, conceptual, and pragmatic work is required to address this. 


\section{Limitations of the research}

This paper presents the evolution of a single service as described by those practitioners involved in the redesign and implementation of the service. Information derived from public health sources on air quality and hospital admission suggest some success in improving outcomes for the population. However, the data were not strong enough to draw any cause-and-effect conclusions. A number of papers ${ }^{18,30}$ have highlighted the difficulties of undertaking research into the effectiveness of redesigned services, and the need for improved methodologies and more integrated working practices between academic researchers and service redesign is required to evidence the full impact of these changes.

\section{Implications for public sector management}

The contribution of this paper lies in its rich description of the translation into practice of features of multiagency professional collaboration that have been described in detail in the theoretical literature. It indicates the potential of nurses to undertake a leading role in initiating and sustaining public health solutions to pressing health care problems. Current literature indicates a cautiousness ${ }^{19,20}$ among primary health care clinicians in relation to networked collaboration as well as considerable challenges for service managers in establishing governance systems which reflect the population focus of this way of working. ${ }^{16,31}$

This paper demonstrates that public sector managers and commissioners need to understand how to support clinicians working across multiagency boundaries, including support for succession planning. This requires improved understanding about how to develop and support health professional leadership skills for collaborative interprofessional practice that does not rely on individual motivation. This presents challenges for service managers and commissioners in providing an enabling framework for public health-orientated clinical practices. This will be of increasing importance in England as the commissioning for public health services and the public health outcomes targets are transitioned from the NHS to local authorities during $2015 .{ }^{32}$

\section{Acknowledgments}

The authors would like to acknowledge Elaine McNeilly, Jo Magnusson, Melissa Chamney, Sally Roberts, and Stephen Abbott who contributed to data collection and analysis at various stages of the PEARLE project. This project was funded by the National Institute for Health Research Health
Services and Delivery Research Programme (project number 08/1605/121).

\section{Disclosure}

The authors report no conflicts of interest in this work. The views and opinions expressed herein are those of the authors and do not necessarily reflect those of the HS\&DR Programme, NIHR, NHS, or the Department of Health.

\section{References}

1. Kendall S, Wilson P, Procter S, Brooks F, Bunn F, McNeilly E. The Nursing Contribution to Models of Chronic Disease Management. Report to NIHR Service Delivery and Organisation Programme. England: 2010. Available from: http://www.netscc.ac.uk/hsdr/files/ project/SDO_FR_08-1605-121_V01.pdf. Accessed August 4, 2014.

2. Procter S, Wilson PM, Brooks F, Kendall S. Success and failure in integrated models of nursing for long term conditions: multiple case studies of whole systems. Int J Nurs Stud. 2013;50(5):632-643.

3. World Health Organisation. Primary Health Care Now More than Ever. Geneva: WHO; 2008.

4. Royal college of physicians (2014) Why asthma still kills. The National Review of Asthma Deaths, Royal college of Physicians, London.

5. Julious SA, Osman LM, Jiwa M. Increases in asthma hospital admissions associated with the end of summer vacation for school-age children with asthma in two cities from England and Scotland. Public Health. 2007;121(6):482-484.

6. Mangan JM, Gerald LB. Asthma agents: monitoring asthma in school. $J$ Sch Health. 2006;76(6):300-302.

7. McWhirter J, McCann D, Coleman H, Calvert M, Warner J. Can schools promote the health of children with asthma? Health Educ Res. 2008;23(6):917-930.

8. Patterson EE, Brennan MP, Linskey KM, Webb DC, Shields MD, Patterson CC. A cluster randomised intervention trial of asthma clubs to improve quality of life in primary school children: the School Care and Asthma Management Project (SCAMP). Arch Dis Child. 2005;90:786-791.

9. Petronella SA, Bricker SK, Perrotta D, Brown C, Brooks EG. Addressing asthma in Texas: development of a school-based asthma surveillance program for Texas elementary schools. J Sch Health 2006;76(6):227-234.

10. Davis A, Savage Brown A, Edelstein J, Tager IB. Identification and education of adolescents with asthma in an urban school district: results from a large-scale asthma intervention. J Urban Health. 2008;85(3):361-374.

11. Bruzzese JM, Evans D, Wiesemann S, et al. Using school staff to establish a preventive network of care to improve elementary school students' control of asthma. J Sch Health. 2006;76(6):307-312.

12. Wilson KD, Moonie S, Sterling DA, Gillespie KN, Kurz RS. Examining the consulting physician model to enhance the school nurse role for children with asthma. J Sch Health. 2009;79(1):1-7.

13. Crouchman C. Teachers views their role in emergency first aid at School. British Journal of School Nursing. 2009;4(1):15-21.

14. Crouchman C. Emergency first aid in School: Teachers' duty of care. British Journal of School Nursing. 2009;4(2):88-89.

15. Public Health England. Health and Care Integration: Making the case from a public health perspective. London: Public Health England; 2013.

16. Mikkelsen-Lopez I, Wyss K, de Savigny D. An approach to addressing governance from a health system framework perspective. BMC Int Health Hum Rights. 2011;11:13.

17. Valaitis R, Martin-Misener R, Wang S, et al. Methods, strategies and technologies used to conduct a scoping literature review of collaboration between primary care and public health 2012. Primary Health Care Research and Development. 13: 219-236. 
18. Gocan S, Laplante MA, Woodend AK. Interprofessional Collaboration in Ontario's. Family Health Teams: A Review of the Literature. J Res Interprof Pract Educ. 2014;3(3).

19. Akhtar-Danesh N, Valaitis R, O’Mara L, Austin P, Munroe V. Viewpoints about collaboration between primary care and public health in Canada. BMC Health Serv Res. 2013;13:311.

20. Kislov R, Walshe K, Harvey G. Managing boundaries in primary care service improvement: a developmental approach to communities of practice. Implement Sci. 2012;7:97.

21. Yin RK. Case Study Research: Design and Methods. 3rd ed. Thousand Oaks, CA; London: Sage Publications; 2003.

22. Wilson PM, Brooks F, Procter S, Kendall S. The nursing contribution to chronic disease management: a case of public expectation? Qualitative findings from a multiple case study design in England and Wales. Int J Nurs Stud. 2012;49(1):2-14.

23. Walters S, Phupinyokul M, Ayres J. Hospital admission rates for asthma and respiratory disease in the West Midlands: their relationship to air pollution levels. Thorax. 1995;50:948-954

24. Price G. Effects of Weather, Air Quality and Geographical Location on Asthma and COPD Exacerbations in the Localities of Worcester and Dudley [PhD thesis]. Coventry: Coventry University; 2007.
25. Department for Education and Skills. National Healthy Schools Status: a Guide for Schools. London: Department of Health; 2005.

26. Department of Health. National Service Framework for Children and Maternity Services. London: Department of Health; 2004.

27. Department for Education and Skills. Every Child Matters: Change for Children in schools. London: Department for Education and Skills; 2004.

28. Department of Health. Guidance on the use of Emergency Salbutamol Inhalers in Schools. London: Department of Health; 2014.

29. Brooks F, Kendall S, Bunn F, Bindler R, Bruya M. The school nurse as navigator of the school health journey: developing the theory and evidence for policy. Prim Health Care Res Dev. 2007;8(3):226-234.

30. Andrews R, Entwistle T. Does Cross-Sectoral Partnership Deliver? An Empirical Exploration of Public Service Effectiveness, Efficiency, and Equity. J Public Adm Res Theory. 2010;20:679-701.

31. Kurunmäki L, Miller P. Regulatory hybrids: Partnerships, budgeting and modernizing government. Management Accounting Research. 2011;22(4):220- 241 .

32. Department of Health. Public Health in Local Government: Commissioning Responsibilities. London: Department of Health; 2011.
Journal of Multidisciplinary Healthcare

\section{Publish your work in this journal}

The Journal of Multidisciplinary Healthcare is an international, peerreviewed open-access journal that aims to represent and publish research in healthcare areas delivered by practitioners of different disciplines. This includes studies and reviews conducted by multidisciplinary teams as well as research which evaluates the results or conduct of such teams or

\section{Dovepress}

healthcare processes in general. The journal covers a wide range of areas and welcomes submissions from practitioners at all levels, from all over the world. The manuscript management system is completely online and includes a very quick and fair peer-review system. Visit http://www.dovepress.com/testimonials.php to read real quotes from published authors. 